\title{
Nihil nocere on the rocky road to endovascular stent-graft treatment
}

\author{
Christoph A. Nienaber, MD \\ Raimund Erbel, $\mathrm{MD}^{\mathrm{b}}$ \\ Hüseyin Ince, $M D^{a}$
}

See related editorial on page 664.

From the Division of Cardiology at the University Hospital Rostock, Department of Internal Medicine, Rostock, ${ }^{\mathrm{a}}$ and GHS Essen, ${ }^{\mathrm{b}}$ Germany.

Received for publication Nov 19, 2003; accepted for publication Nov 24, 2003.

Address for reprints: Christoph A. Nienaber, MD, FACC, FESC, Division of Cardiology, University Hospital of Rostock, Ernst-Heydemann-Str. 6, 18057 Rostock, Germany (E-mail: christoph.nienaber@med. uni-rostock.de).

J Thorac Cardiovasc Surg 2004;127:620-1

$0022-5223 / \$ 30.00$

Copyright $\odot 2004$ by The American Association for Thoracic Surgery

doi:10.1016/j.jtcvs.2003.11.051

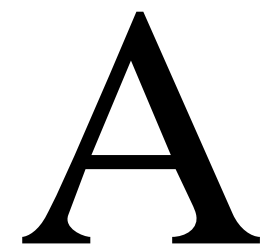

neurysms of the thoracic aorta represent a potentially life-threatening situation, with the risk of rupture increasing with diameter. Surgical resection and interposition of vascular prostheses (Dacron or polytetrafluoroethylene*) have long been considered the standard treatment, despite the substantial risk of severe complications from surgical trauma. Regardless of the great strides in the past decades to improve technique and management, perioperative mortality and morbidity remained high. ${ }^{1-3}$ As a consequence of demographic changes in the Western world, the afflicted population is of increasing age and associated with a variety of comorbidities portending an inherent risk and explaining in part the sobering surgical outcomes. Moreover, perioperative complications ranging from paraplegia to transient renal failure contribute to prolonged hospitalization and high costs. ${ }^{4}$ As a revolutionary alternative,${ }^{5}$ the concept of use of an endovascular stent graft in a patient with a thoracic aortic aneurysm (TAA) emerged a decade ago propelled by the desire (1) to avoid surgical risks by use of a nonsurgical approach and (2) to induce reconstructive remodeling of the diseased aorta by initiating a natural healing process through exclusion and depressurization of the aneurysmal sac. Although initial reports on the endovascular stent-graft strategy were encouraging, ${ }^{6-8}$ randomized data on the use in TAA have not been produced yet, and the smoldering critique has never been fully extinguished.

The article by Demers and colleagues ${ }^{9}$ is provocative and sobering at the same time in its reflection on the late outcomes of 103 patients treated with customfabricated endovascular stent grafts between 1992 and 1997 and followed over 4.5 \pm 2.5 years. Patients considered unfit or not suitable for conventional surgical repair had a 1 - and 5-year survival of $74 \% \pm 6 \%$ and $31 \% \pm 6 \%$, respectively; conversely, patients considered fit even for conventional surgical intervention had a survival after stent-graft placement of $93 \% \pm 4 \%$ and $78 \% \pm 6 \%$, respectively (eg, patients in better health condition fared significantly better). In other words, the health status comprising age and comorbidities is the common denominator for prognosis and not so much the less traumatic treatment concept of endovascular stent grafting.

On first sight, this conclusion is indeed sobering and, to a certain degree, even trivial. Of course, the general state of health is highly important and should always be part of strategic planning in medicine. ${ }^{10}$ Eventually, the observation by Demers and colleagues ${ }^{9}$ documents the final emergence of the philosophical principle of "nihil nocere" (a classic in medicine and surgery) in the brave new interventional world. Demers and colleagues are to be congratulated for critically asking the question of treating nonsurgical candidates at all because stent grafting seems to fail to improve the outcomes of patients unfit for surgical intervention. On a closer look, however, the design of a study comparing the outcomes of surgically fit with unfit patients might leave room for speculation. An ideal study design would compare outcomes of patients in similar health status subjected to either conventional surgical intervention, to nonsurgical stent grafting, or to mere medical treatment. Of course, the design of a prospective study is not feasible for ethical reasons (patients

*Gore-Tex vascular prosthesis, registered trademark of W. L. Gore, Inc, Newark, Del. 
unfit for conventional surgery should of course not undergo surgical intervention); on the other hand, the judgment of unfitness for a major operation and thoracotomy has subjective elements. Ideally, a comparison of natural history with stent-graft placement in 2 groups of patients both considered unfit for surgical intervention because of comorbidities in a prospective registry would best identify the effect of the less traumatic endovascular strategy. These considerations are well known at centers of surgical excellence (such as Stanford), and it appears needless to say that their careful and conservative conclusions deserve our respect because they remember the nihil nocere principle. But although Demers and colleagues found that those patients deemed inoperable had a bleak outcome because of comorbidity and died primarily from medical diseases rather than from aortic rupture and thus challenge the benefit of endovascular stent grafting in cases of asymptomatic TAA, the study is an eye opener in various ways.

First, patients considered in reasonable general health are likely to have an outcome with stent grafting similar or better to that with a conventional operation, and therefore endovascular techniques might represent a true therapeutic alternative for patients with TAA.

Second, patients with TAA and comorbidities are likely to benefit from an appropriate vascular staging strategy to objectively identify and quantify their risk. Staging should include angiographic assessment of the individual cerebral, coronary, and peripheral vasculature with optional catheterbased revascularization or at least optimized medical treatment with $\beta$-blockers, both of which are likely to improve the general health status and thus perioperative outcomes.

Third, miniaturization and refinement of endovascular technology is certainly advancing. Endoaortic interventions will soon be performed percutaneously during local anesthesia, and more physiologic stent grafts will mimic even the rotational 3-dimensional systolic twist of the thoracic aorta, whereas contemporary surgical techniques in TAA are less likely to improve. ${ }^{11-14}$ More importantly, even successful aortic surgery will not abolish any of the associated risk factors from comorbid conditions, and therefore late outcome will remain dominated by the individual prognosis (comorbid state). As a consequence, in centers of excellence for aortic disease, the endovascular treatment options are more likely to prevail, even in highly comorbid subsets of patients, because at least the surgical risk will be eliminated with endovascular techniques.

Finally, a new answer to the ethical question of justification of treatment is not in yet because prospective data from randomized studies or registries are not available nor are standard operational procedures or guidelines. However, if one insists on strict proof (or strict disproof) in empiric science, one will never benefit from experience and never learn from it how wrong one has been. ${ }^{15}$ Nevertheless, even in a world of rapidly advancing technology, it is ironically still wise to remember old principles of responsible use of clinical judgment and experience for the benefit of our patients. The growing segment of older patients with multiorgan comorbidities deserve a holistic approach, the intelligent use of prognosticating tools, and close interdisciplinary cooperation in a medicoethical framework. ${ }^{16}$

\section{References}

1. Borst HG, Jurmann M, Buhner B, et al. Risk of replacement of descending aorta with a standardized left bypass technique. $J$ Thorac Cardiovasc Surg. 1994;107:125-33.

2. Ince H, Nienaber CA. Stenting versus surgery of the thoracic aorta. J Interv Cardiol. 2000;13:469-74.

3. Najafi H. 1993 update: descending aortic aneurysmectomy without adjuncts to avoid ischemia. Ann Thorac Surg. 1993;55:1042-5.

4. Gawenda M, Zaehringer M, Brunkwall J. Open versus endovascular repair of para-anastomotic aneurysms in patients who were morphological candidates for endovascular treatment. J Endovasc Ther. 2003; 10:745-51.

5. Volodos NL, Karpovich IP, Troyan VI, et al. Clinical experience of the use of self-fixing synthetic prostheses for remote endoprosthetics of the thoracic and the abdominal aorta and iliac arteries through the femoral artery and as intraoperative endoprosthesis for aorta reconstruction. Vasa. 1991;33(suppl):93-5.

6. Dake MD, Miller DC, Semba CP, et al. Transluminal placement of endovascular stent-grafts for the treatment of descending thoracic aortic aneurysms. N Engl J Med. 1994;331:1729-34.

7. Mitchell RS, Dake MD, Semba CP, et al. Endovascular stent-graft repair of thoracic aortic aneurysms. J Thorac Cardiovasc Surg. 1996; 111:1054-62.

8. Ehrlich M, Grabenwöger M, Grimm M, et al. Endovascular stent graft repair for aneurysms on the descending thoracic aorta. Ann Thorac Surg. 1998;66:19-24.

9. Demers P, Miller DC, Mitchell RS, et al. Midterm results of endovascular repair of descending thoracic aortic aneurysms with first-generation stent grafts. J Thorac Cardiovasc Surg. 2004;127:664-73.

10. Mehta RH, Suzuki T, Hagan PG, et al. Predicting death in patients with acute type a aortic dissection. Circulation. 2002;105(2):200-6.

11. Lachat M, Pfammatter T, Turina M. Transfemoral endografting of thoracic aortic aneurysm under local anesthesia: a simple, safe and fast track procedure. Vasa. 1999;28:204-6.

12. Quinn SF, Duke DJ, Baldwin SS, et al. Percutaneous deployment of a low-profile bifurcated stent-graft. AJR Am J Roentgenol. 2002;178: 654-6.

13. von Segesser LK, Killur I, Jenni R, et al. Improved distal circulatory support for repair of descending thoracic aortic aneurysms. Ann Thorac Surg. 1993;56:1373-80.

14. Safi HJ, Campbell MP, Ferreira ML, et al. Spinal cord protection in descending thoracic and thoracoabdominal aortic aneurysm repair. Semin Thorac Cardiovasc Surg. 1998;10:41-4.

15. Popper KR. On the problem of a theory of scientific method. In: The logic of scientific discovery. London: Routledge; 1992.

16. Nienaber CA, Eagle KA. Aortic dissection: new frontiers in diagnosis and management; part II: therapeutic management and follow-up. Circulation. 2003;108:772-8. 